\title{
AN EXAMINATION OF LAND USE IN THE AMASYA DEVELOPMENT PLAN THROUGH CLUSTER ANALYSIS
}

\author{
ERGEN, M. ${ }^{1 *}-$ ERGEN, Y. B. ${ }^{2}$ \\ ${ }^{I}$ Department of Architecture, Faculty of Fine Arts and Design, Siirt University, Siirt, Turkey \\ ${ }^{2}$ Department of Urban and Regional Planning, Faculty of Fine Arts and Design, Siirt \\ University, Siirt, Turkey \\ *Corresponding author \\ e-mail: mustafaergen2002@yahoo.com; phone: +90-537-911-4234
}

(Received $26^{\text {th }}$ Feb 2019; accepted $1^{\text {st }}$ Jul 2019)

\begin{abstract}
In this study, existing and future land use patterns were examined in the development plan for Amasya using hierarchical cluster analysis. To this end, the area encompassed by the Amasya development plan was partitioned into grids to examine their proximities and similarities to each other in terms of land use. In addition, linkages among the grids were investigated with respect to the land use patterns. Linkages among land use functions were determined in this research through cluster analysis. After exposing the similarities among the grids, the shortcomings with regard to the necessary social infrastructure within the grids were identified, and the requirements of similar urban development approaches to grids with similar characteristics were described. This paper emphasizes the need for healthy, sustainable development and a planned and balanced distribution of social infrastructure in urban development plans.
\end{abstract}

Keywords: land use patterns, grids, hierarchical cluster analysis, social infrastructure, similar characteristics

\section{Introduction}

The way in which land is used can provide essential resources and is one of the most central factors that affect urban development (Foley et al., 2005; Niedertscheider and Erb, 2014). This important factor reveals that city planning must use sustainable approaches that satisfy human needs. For this to be successful, it is imperative to fully understand how land is categorized in city development plans. Numerous land use factors, such as green space and housing space, shape how urban areas should be developed. For example, housing space shapes urban development by providing living quarters for current and future populations, and this basic necessity can be constructed when urban development is correctly planned.

In Turkey, land use issues in urban areas cannot be resolved using only ad-hoc solutions. There exists a significant deficit of knowledge regarding land use factors in cities as well as how land is used (Niedertscheider and Erb, 2014). As a precondition in preparing for future land use modifications, land use decisions to changes in previous underlying development must be analyzed (Dearing et al., 2010; Niedertscheider and $\mathrm{Erb}, 2014)$. Hierarchical analysis is regarded as one of the most powerful instruments ( $R$ Core Team, 2015; Manjunath et al., 2018) by which to understand future development options that affect current land use. Many studies on land use changes are highly limited mainly because of the lack of data sets on land systems and dynamics as well as the underlying factors that affect these changes (Singh et al., 2013; Niedertscheider and Erb, 2014). 
Results of studies on urban development plans in Turkey are conducted to work in concert with planning requirements, a balanced distribution of social and technical infrastructure, and in accordance with standards and needs. For example, in Turkey's development plans, the distribution of and need for green areas per person or the distance to neighborhood schools are important for healthy urbanization. A $10 \mathrm{~m}^{2}$ green area/capita should be included in all urban development plans. When we analyzed the urban structure of Amasya, we found that a linear urban structure is formed between the Yeşilırmak River and two mountain ranges. This situation creates problems for physical expansion of the city, because the topography in Amasya is not flat enough to accommodate sufficient residential and development areas. Because of this topography, a balanced distribution of social infrastructure in urban development is indispensable for a healthy urban structure.

Balanced distribution means that the population living within any city grid has equal access to all social facilities, and that all social facilities appeal equally to everyone, or that the population is distributed evenly within each grid. In short, balanced distribution describes how urban development within each grid is self-sufficient and does not need external intervention. The grids contain urban land use forms which are created by Municipality for the future urban development in Amasya. Types of land uses come from legal Municipality creation into the grids. It is proved that the form of land uses is the main research data for analysing grids and current Amasya city development condition.

Cluster analysis is a suitable method by which to identify analogous groups of objects called "clusters" (Mooi and Sarstedt, 2011). A central feature of this analysis is its ability to refer directly to either understanding development options or to land use relationships in this study (Alvarenga et al., 2013; Niedertscheider and Erb, 2014). The core area of urban usage is the transition zone between land use similarities and differences (Bo, et al., 2011). The approaches to the similarities and differences in this cluster analysis provided us with ideas about land use distribution, which supported our deductions related to recent land use and the social infrastructure. In addition, cluster analysis is a highly useful method by which to understand the trends in urban development for future perspectives.

Land use change is defined as a transformation of one land use into another format, or a complete change from an old land use to a new land use (Liu et al., 2014). There are many studies related to land use change (McHarg, 1992; Erickson, 1995; Milesia et al., 2003; Nuissl et al., 2009; Song, et al., 2013; Cinelli, et al., 2014; Liu et al., 2014; Krekel, et al., 2016; Lu and Ke, 2018). It is important to study land use development because it has a profound impact on options for future city development (Liu et al., 2014). This paper brings together, in a systematic way, the results of many recent studies on urban form, especially on land use (Ozus et al., 2012).

In their 2014 research, Grecchi, et al. investigated changes in land use using raster data from different dates. Another 2014 study by Kline et al. analyzed land use plans within different governing regimes. Likewise, Sharifi et al. (2014) investigated the regulation and control over master plans for urban growth using monitoring, and Liu et al., 2014 conducted a compatibility analysis for land use, which identified compatibility analysis criteria, such as topography, geology, and socioeconomics. The monitoring method is most prevalent in land use analyses. In their study, Ozus et al. (2012) used cluster analysis to examine how travel demand shaped the spatial structure of Istanbul; however, land use that does not involve transportation is also important. We use a 
cluster analysis of land use patterns to demonstrate a more effective use of this method in planning. This study also presents the urban social infrastructure issues, such as easy access to primary schools and enough green areas per person, using an agglomerative hierarchical cluster analysis. This identifies the social infrastructure problems in urban development and is a departure from other studies because it emphasizes the need for an innovative and comprehensible approach to land use. In this context, an innovative approach refers to identifying the current distribution of the social infrastructure and the necessary strategies for the future by looking at existing land use within the city.

In addition, the methods used in the present study to analyze land use suitability first emerged in 1992 with Ian McHarg's Design with Nature and are still used today in many studies. In 200 the results of a study by Randolph showed that land use suitability analysis provided information about lands suitable for settlement or about the most suitable settlement areas for land use and their development based on specific criteria. This study was not to determine the most suitable areas for settlement but to determine the distribution of social service areas within the city and designated in the development plans that the municipalities are supposed to follow and to choose the areas of social infrastructure in urban areas and determine the similarities among them in the city grids. The similarities among these areas reveal an analysis of the current situation, such as whether development has been homogeneous, and can generate prospective inferences. Our analysis is based on the current situation for land use in urban areas and does not consider settlement or suitability for future development.

From this study, the best planning approaches used for urban planning are presented to help facilitate effective and more resolution-oriented decisions to enable an understanding of land use areas. For example, it is necessary to determine where within the city there is a lack of social facilities and to decide within which areas these facilities will be designed. It is also important to create suitable designs for this area, to fill the need for urban social facilities within the city, and to resolve the deficiencies in urban design and urban planning within the city's existing development.

The aim of this study was to explore the direction that future social infrastructure development within Amasya will take by analyzing its land use using the cluster analysis method. Land use is the most important dimension of urban development within cities, and its intensity has become an important indicator of the relationship between current and future urban development (Hubacek and van den Bergh, 2006; Shi and $\mathrm{Yu}, 2014)$. Moreover, in the study, the distribution of spaces in terms of their land use similarities and differences will be investigated to make recommendations for future urban development. This new methodological approach will provide a new perspective to development plans in Turkey. These similarities and differences will be useful for illustrating the imbalances of social infrastructures in land use and identifying whether the Amasya can provide sufficient infrastructure within every region and every area to accommodate its citizens. Accordingly, this paper will focus on the necessity of reanalyzing the city's approach to creating social infrastructure that is incorporated into urban development plans.

This study presents a land use analysis that is used to assess development options in Amasya. The hierarchical analysis helps to analyze urban development by providing a good assessment of land use development while revealing the similarities and dissimilarities among the various urban spaces. Our main research questions are as follows: how well is the social infrastructure, such as green areas, schools, and hospitals, throughout an urbanized area distributed as it is intended (e.g., primary 
schools within a perimeter of 500-m of settlements, or green areas should be $10 \mathrm{~m}^{2} /$ person) and is it balanced? If there is an unbalanced distribution of social infrastructure, what do we need to do to balance the distribution of that infrastructure in future urban development plans? The second question will be important when discussing how the social infrastructure will be planned in future urban development and how the lack of social infrastructure within the city will be alleviated. Using an agglomerative hierarchical cluster analysis, this research investigated the sufficiency of urban social infrastructure and whether urban areas have been developed in a healthy manner.

\section{The role of cluster analysis in planning practices}

There is a wide variety of planning practices with different purposes in Turkey's land planning system. Among Turkey's planning stages, cluster analysis is most useful for land use plans, one category of plans. We conducted our analysis at this planning stage because land use plans provide the existing land use patterns during the decisionmaking process. Although this method was chosen specifically for Turkey's planning system, it can be used for any country and on any land use plan because it increased information on the quality of life within the regions studied. With this method, existing land use can be accurately determined, and a planning process can be created accordingly. The following text explains this more clearly by providing a hierarchical scheme of the plans in Turkey's planning system (Fig. 1) with additional social infrastructure within the new developments.

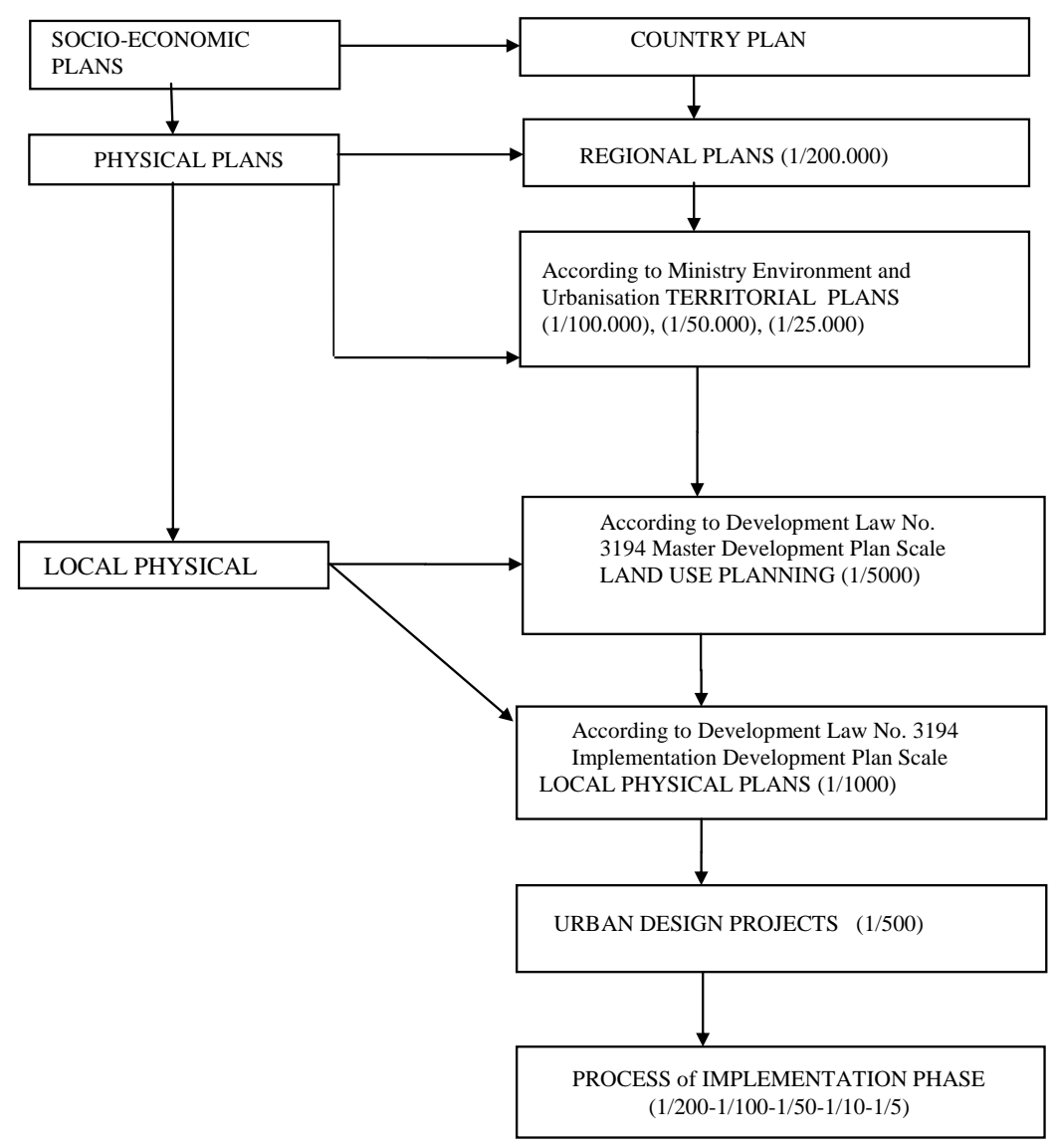

Figure 1. Turkish planning system. (Source: Türk, 2002) 
The area studied was divided into grids. The characteristic feature of each grid is to be a homogeneous distribution of mixed land use and have the ability to describe the necessary services, such as hospitals, schools, and recreational areas (social infrastructure), that are included in land use and urban development. The square grids are used to investigate the distribution of social infrastructure within $\sim 500 \mathrm{~m}$ of the center of the city, which also helped understand which social infrastructure is accessible in each grid. The fact that the grids offer the opportunity to develop a planning approach that is a sounder, sustainable, and provides accessible social infrastructure and has a command of the entire city reveals the most significant feature of this arrangement - the location of these social infrastructures. The need for social services within the grid areas that do not have them is not emphasized, and the study does not suggest that the needs be satisfied. Thus, the results provide information on how social infrastructure is distributed within the grids and how the transportation issues and other recommendations were resolved.

The grids included all areas within the borders of the municipal adjacent areas. If each social service and the population within the grids were to be discussed presumptively and evenly, there would be equal and balanced distribution within the city. We recognize that this approach is similar to developing an imaginary ideal city, and the aim here is not to disperse the population accordingly, but to understand and explain how urban areas would be developed in such cases. Keeping the same populations within each grid is an imaginary approach, and dispersing a population according to ideal land use is impossible and meaningless. The population of Amasya is 113.932 (Turkstat, 2018), and a balanced plan should propose a balanced distribution of the city's population. If we can employ approximately 3.452 people within each grid, we can have a balanced distribution of housing as well. The acceptable size of housing per person is between 12 and $24 \mathrm{~m}^{2}$ in Turkey's planning system and, accordingly, the maximum area of housing within the grid is $82.848 \mathrm{~m}^{2}$. According to legislation, land use planning administrators in Turkey are obligated to designate $10 \mathrm{~m}^{2}$ of green area/person in a development plan; therefore, $34.520 \mathrm{~m}^{2}$ within each grid must be designated as green areas. Moreover, hospital building floor space must be $0.11 \mathrm{~m}^{2} /$ person, which means that $379.5 \mathrm{~m}^{2}$ of building floorspace must be designated as hospital building floorspace within each grid. The total area for healthcare services includes other facilities, such as $0.05 \mathrm{~m}^{2} /$ person $\left(172.6 \mathrm{~m}^{2}\right)$ for dispensaries and $0.15 \mathrm{~m}^{2} /$ person $\left(517.8 \mathrm{~m}^{2}\right)$ for other facilities; therefore, total healthcare space within each grid would be $1069.9 \mathrm{~m}^{2}$. However, it is highly likely that the existing land use situation is not similar to this, in which case, it is necessary to take measures to correct the situation with additional social infrastructure within the new developments.

\section{Materials and methods}

\section{Area of study}

Figure 2 shows the boundaries of the center of Amasya and the area analyzed for this research. Amasya is located in the Black Sea Region of Turkey and is surrounded by Tokat on the east, Tokat and Yozgat on the south, and Samsun on the north (Turkstat, 2012). Amasya's average altitude is $1150 \mathrm{~m}$, with the altitude in the center of the city being only $411 \mathrm{~m}$. The city is located between the east longitudes of $34^{\circ} 57^{\prime} 06^{\prime \prime}-$ $36^{\circ} 31^{\prime} 53^{\prime \prime}$ and the north latitudes of $41^{\circ} 04^{\prime} 54^{\prime \prime}-40^{\circ} 16^{\prime} 16^{\prime \prime}$ (Turkstat, 2012). 
Archaeological excavations have revealed that the city dates back 7500 years, making it one of the most important cities in history (Governorship of Amasya, 2017).

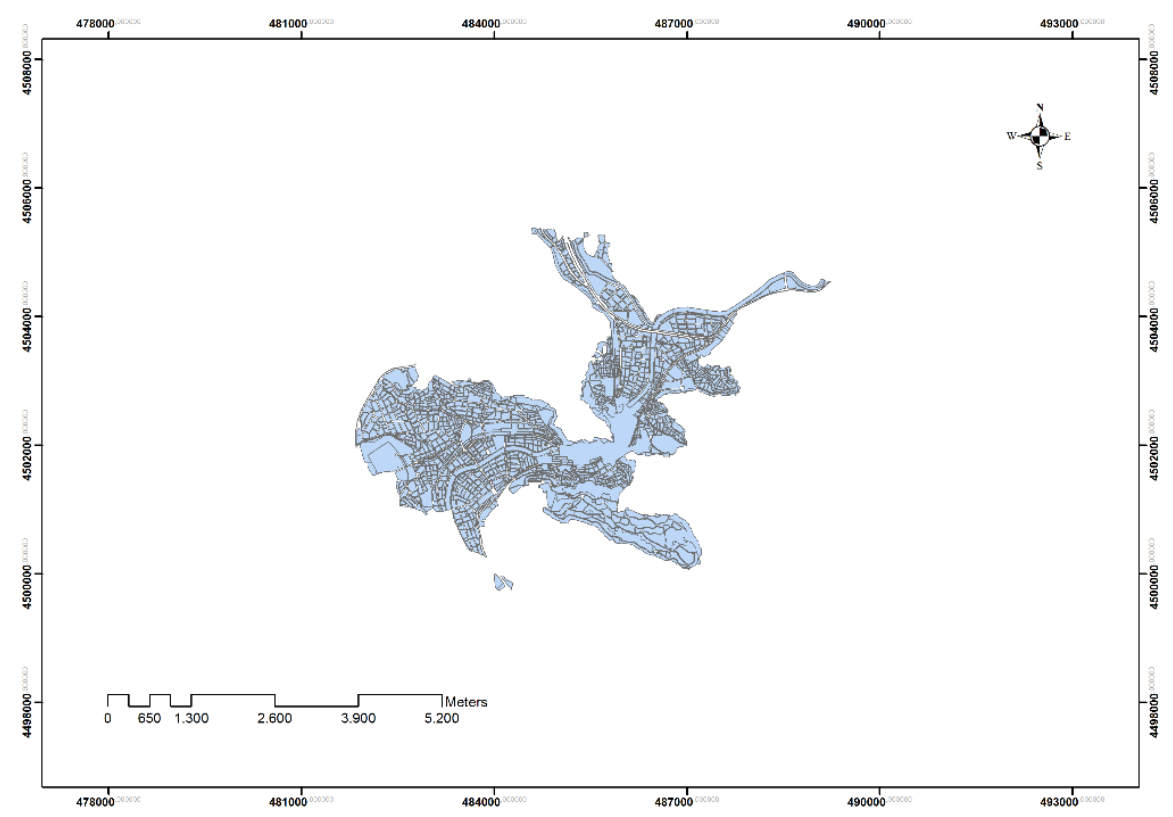

Figure 2. The analysis area of Amasya, Turkey. (Source: The map was obtained from Amasya Municipality with NetCAD program. The map was converted to ArcGIS and prepared by the authors for description of analyzing areas in Amasya)

The methods used are based on a case study of Amasya. It was evident from the findings that Amasya was most likely a city in which traditional urban planning practices would have been the norm. In Turkey, such practices always lack adequate social infrastructure; therefore, in this article, analyses are conducted on how the urban development plans should be constructed, using Amasya as an example.

\section{Materials}

Urban development plans can be obtained from municipal authorities in Turkey in which the administrators are obligated to prepare development plans for each municipality. A development plan is a periodic study that is required to ensure healthy urban development. Moreover, development plans are prepared using up-to-date information on land use; therefore, in our research, the analyses use development plans that were prepared by the Amasya Municipality. The data for this research were obtained from these urban development plans and analyzed using cluster analysis. Thirty-three grids were produced using the urban development plans with the help of ArcGIS based on the land use data (Fig. 3). To explain the methods, we used the Lance-Williams algorithm, which was formulated in 1967 by Lance and Williams as follows (Eq. 1):

$$
d(i+j, k)=a_{i} d(i, k)+a_{j} d(j, k)+b, d(i, j)+c|d(i, k)-d(j, k)|
$$


The formula displays the distance between clusters $\mathrm{k}$ and $\mathrm{i}+\mathrm{j}$. This study addresses the similarities and dissimilarities between data using single linkage, average linkage, and complete linkage cluster analyses, which are part of the agglomerative hierarchical analysis.

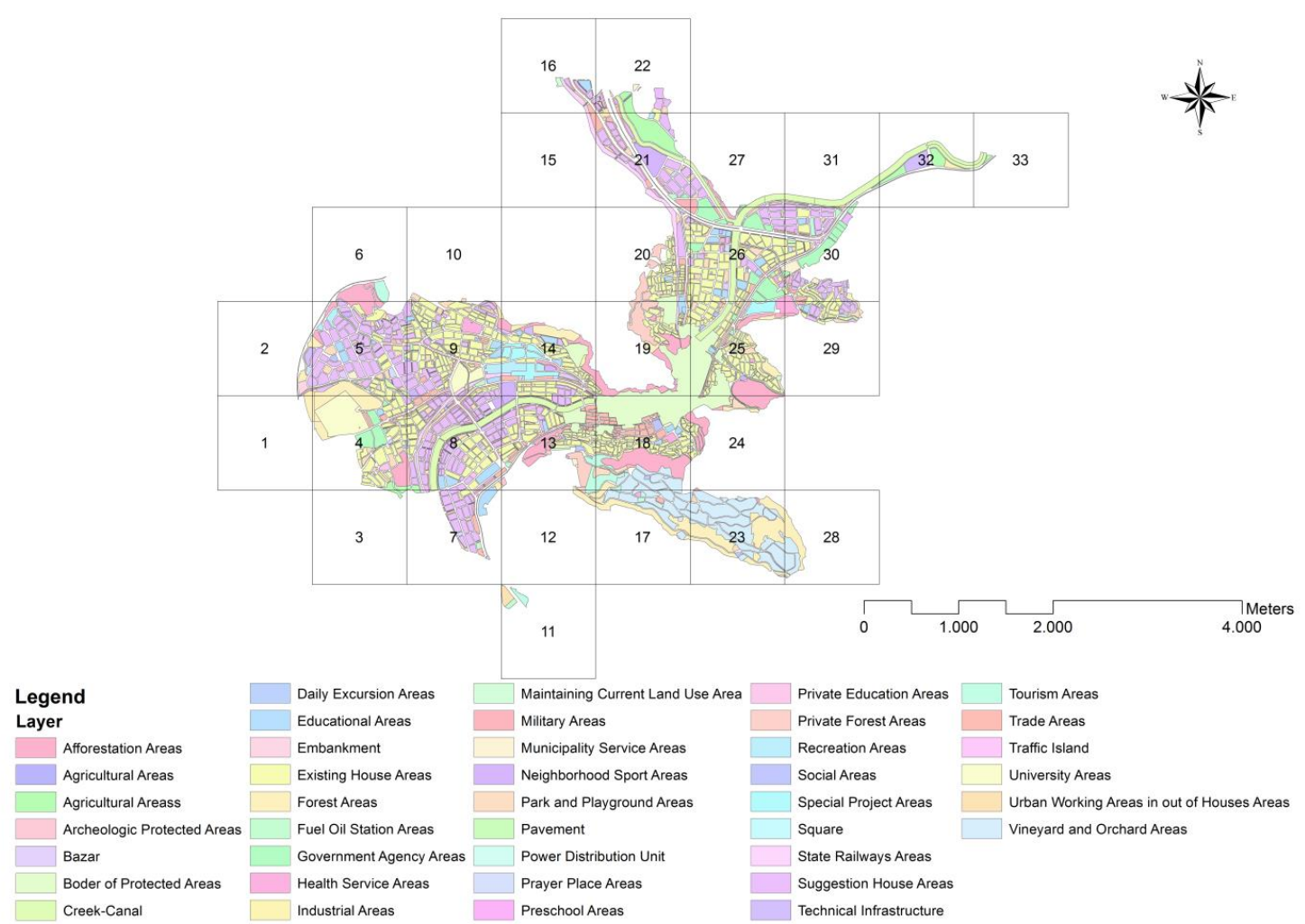

Figure 3. Land Use and Grids of Study Area. (Source: The map was obtained from Amasya Municipality in a GIS format. The map was converted to ArcGIS and prepared by the authors for analyzing land uses in Amasya)

The data on the land use map were first transformed from the NetCAD format to the ArcGIS format. To make them suitable for analysis, georeferences were created in ArcGIS WGS 1984 Universal Transverse Mercator (UTM) Zone. Grids were produced within ArcGIS, and data were obtained for each grid. The raw data obtained were normalized using Matedit to make them analyzable. We began by normalization the analysis to eliminate redundant variables in the database. Then, we conducted an agglomerative hierarchical analysis using Minitab. The results obtained from this analysis revealed the urban development approaches for similar and different grids. Hawth's analysis tools in ArcGIS automatically generated the grids. Using the UTM zone, these tools generated equal $1-$ by $1-\mathrm{km}$ squares. By doing so, we were able to analyze the included land uses and the values of the social infrastructure within the land uses. Using this program, analyses conducted for future land development will shed light on future advances. Each grid allowed for meaningful analyses that could be conducted based on Hawth's analysis tools. We determined that conducting these analyses using smaller or larger grids would not be feasible. 
Cluster analysis is used in many research studies, including the wastewater treatment study byBayo and Castellanos (2016), who matched the similarities in the cluster analysis to principal factors to attain results, and the research conducted by Ozus et al. (2012), who used a hierarchical cluster analysis to identify similar transportation behaviors among districts within Istanbul. As mentioned, agglomerative hierarchical cluster analysis is a widely used method, and unlike those used in other studies, this method is used in our research to identify how urban land use is distributed and determine the distribution of social infrastructure areas within the city grids.

Agglomerative hierarchical cluster analysis was chosen to study land use patterns using data obtained on decisions from the city's urban land use plan. In this sense, cluster analysis can be used as a tool to analyze only land use development, and allows us to examine the required healthcare, housing, and green spaces for 100 ha of land and to make better planning decisions. After selecting the best cluster analysis, the information necessary to plan similar and different places within that grid is provided.

\section{Methodology}

All grids were created using the same method with GEOSTAT, which comprises all of the urban areas in Europe and divides them into grids. The GEOSTAT grid size of $1 \mathrm{~km}^{2}$ is based on a population density of at least 5000 people within an area of $300 \mathrm{~km}^{2}$ (Paffi et al., 2016). The grids created in this study were applied to the entire city. The aim was to ensure that the populations living within each region of the city were equally represented and had equal accessibility to the city's social facilities; therefore, this study sought to research and identify how much of the population living within each city grid actually realized that goal.

One of the key rules in this method is that grids be a particular uniform size. In these grids of a predetermined size, it was not necessary to have either all or part of the land use plan. The number of grids, which is determined by applying an area of particular size in the land use plan, is used as the basis. Thus, it is important to divide the selected area into grids rather than to divide the area of the plan into grids. As a result of the analyses, 33 grids were created using Hawth's analysis tool. Each equal grid provides a way by which to analyze the land use of the entire area. In some of the emerging grids, there was very little area available for land use, the most important reason for which is that land use divided into equal grids decreases at the edges of the city and intensifies at the focal points of urbanization; however, our tools offered the opportunity to analyze both the farthest point and the most intensely urbanized area within the equal grid areas.

\section{Agglomerative hierarchical analysis}

Cluster analysis is a form of statistical analysis used for examining multivariate data with the objective being to uncover or discover groups or clusters that are similar to and different from each other (Everitt, 2005; Ozus, et al., 2012). Cluster analysis is linked to a correlation matrix; however, it can generally conduct analyses in different forms (Robinson, 1998).

In our study, cluster analyses were performed using the linkage method. Through these analyses, grids with the highest proximity and those with the most linkages were identified. Using the linkage method, proximities among the grids were calculated on the basis of the correlations among them. As stated, three types of linkage methods were used in our study. 
At the analysis stage, the cophenetic correlation method was used to find the best approach to agglomerative hierarchical cluster analysis and to be able to conduct the related analyses. This is the best method by which to understand the phenomenon of future urban development. Accordingly, the current situation in urban development sheds light on future approaches to development.

\section{Identifying the best cluster approach}

Clusters were validated using the cophenetic correlation, a commonly used measurement in hierarchical clustering (Ozus et al., 2012). The Matlab code given below was used for this analysis (Anonymous, 2018):

$$
\begin{gathered}
c=\operatorname{cophenet}(Z, Y) \\
{[c, d]=\operatorname{cophenet}(Z, Y)}
\end{gathered}
$$

In the cophenetic correlation coefficient values, the best cluster analysis linkage method is identified when the value of $\mathrm{r}$ approaches 1 . Conversely, if the value approaches the linkage method should not be chosen. As the Table 1 illustrates, all linkage methods in the cophenetic correlation coefficient analysis could be used for this analysis. It also shows that average linkage was the best approach, although all were similar. Accordingly, groupings of clusters on the map, which were created using average linkage, are described here and shown in Figure 4.

In addition, grids and land uses were correlated to better understand the linkages among them, and the findings were evaluated. Data on the current state, obtained using the average linkage method, will influence planning decisions.

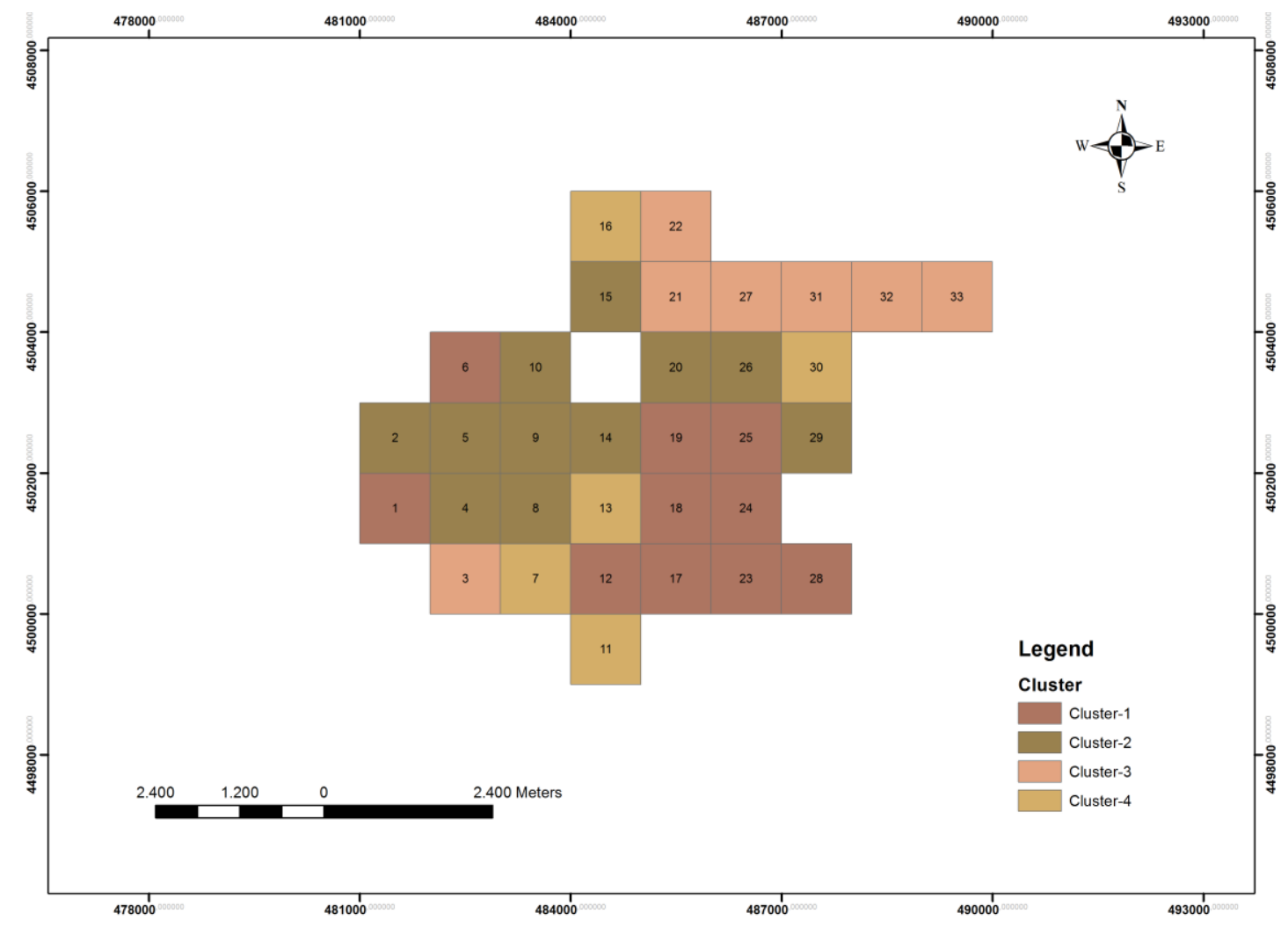

Figure 4. Clustering analysis map created using grids and average linkage 
Table 1. The cophenetic correlation coefficient values

\begin{tabular}{c|c}
\hline Linkage method & Cophenetic correlation coefficient \\
\hline Single linkage & $\mathrm{r}=0.8211$ \\
Complete linkage & $\mathrm{r}=0.8043$ \\
Average linkage & $\mathrm{r}=0.8285$ \\
\hline
\end{tabular}

\section{Results}

\section{Average linkage cluster}

In average linkage analysis, the average distance between two clusters is considered. Average linkage was formulated by the Lance-Williams algorithm created in 1967 by considering the average distances between the clusters of $i+j$ and $k$.

$$
\mathrm{d}(\mathrm{Ci}, \mathrm{Cj})=\frac{1}{n j+n i} \sum_{a \in C i, a \in c j} d(a, b)
$$

In the analyses performed using Minitab, the following average linkage results were obtained (Fig. 5).

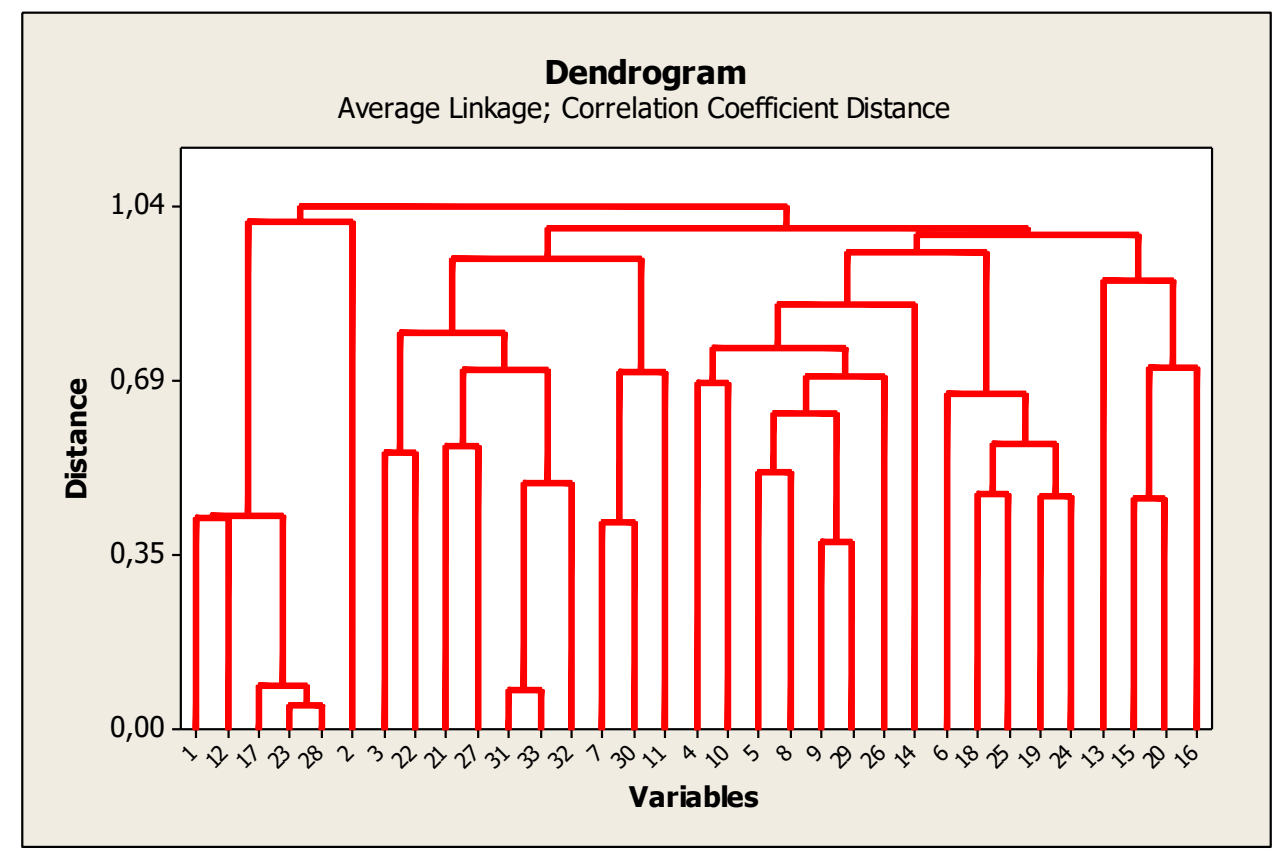

Figure 5. Dendrogram for average linkage analysis

The similarity between the $23^{\text {rd }}$ and the $28^{\text {th }}$ grids is striking (Table 2). It can be seen from Table 2 that the similarity level, 9.642 and distance, 0.0471 stand out. The $1^{\text {st }}$ and $3^{\text {rd }}$ grids are those that are the most distant from each other. While the similarity level is 48.023 the distance level is 1.03953 .

Here are the clusters that result; Cluster-1: Grid- Grid-1 Grid-1 Grid-2 Grid-2 GridGrid-1 Grid-2 Grid-1 Grid-2 Cluster-2: Grid- Grid- Grid-2 Grid-1 Grid-1 Grid-2 GridGrid-1 Grid- Grid- Grid-26 Cluster-3: Grid- Grid-2 Grid-2 Grid-2 Grid-3 Grid-3 Grid-3 Cluster-4: Grid- Grid-3 Grid-1 Grid-1 Grid-16. 
Table 2. Correlation coefficient distance, average linkage amalgamation steps

\begin{tabular}{|c|c|c|c|c|c|c|c|}
\hline Step & $\begin{array}{l}\text { Number of } \\
\text { clusters }\end{array}$ & $\begin{array}{c}\text { Similarity } \\
\text { level }\end{array}$ & $\begin{array}{c}\text { Distance } \\
\text { level }\end{array}$ & \multicolumn{2}{|c|}{$\begin{array}{c}\text { Clusters } \\
\text { joined }\end{array}$} & $\begin{array}{l}\text { New } \\
\text { clusters }\end{array}$ & $\begin{array}{c}\text { Number of } \\
\text { observation in new } \\
\text { cluster }\end{array}$ \\
\hline 1 & 32 & 97.6422 & 0.04716 & 23 & 28 & 23 & 2 \\
\hline 2 & 31 & 96.1314 & 0.07737 & 31 & 33 & 31 & 2 \\
\hline 3 & 30 & 95.7281 & 0.08544 & 17 & 23 & 17 & 3 \\
\hline 4 & 29 & 81.2948 & 0.37410 & 9 & 29 & 9 & 2 \\
\hline 5 & 28 & 79.4171 & 0.41166 & 7 & 30 & 7 & 2 \\
\hline 6 & 27 & 79.0926 & 0.41815 & 1 & 12 & 1 & 2 \\
\hline 7 & 26 & 78.8213 & 0.42357 & 1 & 17 & 1 & 5 \\
\hline 8 & 25 & 77.0723 & 0.45855 & 15 & 20 & 15 & 2 \\
\hline 9 & 24 & 76.8737 & 0.46253 & 19 & 24 & 19 & 2 \\
\hline 10 & 23 & 76.6006 & 0.46799 & 18 & 25 & 18 & 2 \\
\hline 11 & 22 & 75.4615 & 0.49077 & 31 & 32 & 31 & 3 \\
\hline 12 & 21 & 74.5501 & 0.50900 & 5 & 8 & 5 & 2 \\
\hline 13 & 20 & 72.6308 & 0.54738 & 3 & 22 & 3 & 2 \\
\hline 14 & 19 & 71.9760 & 0.56048 & 21 & 27 & 21 & 2 \\
\hline 15 & 18 & 71.7084 & 0.56583 & 18 & 19 & 18 & 4 \\
\hline 16 & 17 & 68.6349 & 0.62730 & 5 & 9 & 5 & 4 \\
\hline 17 & 16 & 66.6087 & 0.66783 & 6 & 18 & 6 & 5 \\
\hline 18 & 15 & 65.6034 & 0.68793 & 4 & 10 & 4 & 2 \\
\hline 19 & 14 & 64.8900 & 0.70220 & 5 & 26 & 5 & 5 \\
\hline 20 & 13 & 64.5707 & 0.70859 & 7 & 11 & 7 & 3 \\
\hline 21 & 12 & 64.3221 & 0.71356 & 21 & 31 & 21 & 5 \\
\hline 22 & 11 & 64.0159 & 0.71968 & 15 & 16 & 15 & 3 \\
\hline 23 & 10 & 62.1014 & 0.75797 & 4 & 5 & 4 & 7 \\
\hline 24 & 9 & 60.7311 & 0.78538 & 3 & 21 & 3 & 7 \\
\hline 25 & 8 & 57.7172 & 0.84566 & 4 & 14 & 4 & 8 \\
\hline 26 & 7 & 55.3648 & 0.89270 & 13 & 15 & 13 & 4 \\
\hline 27 & 6 & 53.1801 & 0.93640 & 3 & 7 & 3 & 10 \\
\hline 28 & 5 & 52.6014 & 0.94797 & 4 & 6 & 4 & 13 \\
\hline 29 & 4 & 50.9603 & 0.98079 & 4 & 13 & 4 & 17 \\
\hline 30 & 3 & 50.2563 & 0.99487 & 3 & 4 & 3 & 27 \\
\hline 31 & 2 & 49.6676 & 1.00665 & 1 & 2 & 1 & 6 \\
\hline 32 & 1 & 48.0233 & 1.03953 & 1 & 3 & 1 & 33 \\
\hline
\end{tabular}

A landuse development model can be created based on decisions made from data obtained using the average linkage method. To understand the balanced distribution of land use with respect to accessibility to the services (such as schools, hospitals etc.), information on land use must be gathered and the lack of efficient social infrastructure must be identified. Efficient use of the land helps create sustainable and habitable cities by ensuring a sufficiently balanced hospital accessibility, green areas per person in square meters (or other ratio), or other infrastructure in urban development. In this sense, average linkage, which is obtained using the cophenetic coefficient correlation 
method in agglomerative hierarchical cluster analysis is the best approach. Thus, our findings in this study were evaluated using this type of analysis.

The results from our cluster analyses illustrated land use within each grid. With specific regard to how social infrastructure is distributed by identifying similar and different land uses within each grid and which precautions we should take in urban development plans based on these results, this study was able to obtain results that would help guide future planning. The results of the similar and different grids are provided below.

In the average linkage analysis, the $23^{\text {rd }}$ and $28^{\text {th }}$ grids emerged as the most similar; therefore, land use in these grids was examined in more detail. The $23^{\text {rd }}$ grid comprised $0.43 \%$ social areas, $1.56 \%$ park and playground areas, $36.80 \%$ forest areas, $0.52 \%$ afforestation areas, and $60.69 \%$ vineyard and orchard areas. On the other hand, the $28^{\text {th }}$ grid comprised $50.52 \%$ forest areas and $49.48 \%$ vineyard and orchard areas. We observed that these grids are mostly composed of green spaces, although we also observed that urban development is slowly emerging within the $23^{\text {rd }}$ grid. The observation that these two grids are near each other suggests that urban development within the $23^{\text {rd }}$ grid will pose a threat to the green spaces within the $28^{\text {th }}$ grid.

Using average linkage, we observed that the $1^{\text {st }}$ and $3^{\text {rd }}$ grids are most distant from each other. Murtagh and Legendre (2011) reported that the study conducted using the Lance-Williams (1967) used controlled dissimilarity of object distance for cluster analysis. In the present study, the differences among the grids were analyzed using cluster analysis, which found the most distance between the $1^{\text {st }}$ and $3^{\text {rd }}$ grids. In addition, the program that was used statistically analyzed the differences among the grids; therefore, we can consider that the $1^{\text {st }}$ and $3^{\text {rd }}$ grids are different from each other. Grid 1 comprises $3.6 \%$ traffic islands and $96.4 \%$ forest areas, whereas $100 \%$ of grid3 is composed of agricultural areas. The fact that, in particular, grid 1 contains traffic islands implies that this space will threaten forest areas in the future; however, it can be argued that the same urban development approach should not be recommended for these spaces because the grids are highly dissimilar and that grid which consists of forest areas, does not have traffic islands.

Grids 5 and 9 emerged as not entirely the same but also not too distant from each other. These grids are located nearly in the middle in all three linkage methods. Grid5 comprises university areas $(0.64 \%)$, tourism areas $(0.14 \%)$, power distribution areas $(0.14 \%)$, existing house areas $(10.95 \%)$, technical infrastructure areas $(0.28 \%)$, trade areas $(0.71 \%)$, social areas $(0.71 \%)$, neighborhood sport areas $(0.71 \%)$, health service areas $(0.36 \%)$, recreational areas $(1.92 \%)$, median strips $(0.21 \%)$, trade areas $(0.85 \%)$, park and playground areas $(7.32 \%)$, private education areas $(0.36 \%)$, educational areas $(2.56 \%)$, forest areas $(9.31 \%)$, suggested house areas $(51.10 \%)$, municipality service areas $(0.85 \%)$, a creek-canal $(3.20 \%)$, afforestation areas $(6.68 \%)$, and places of worship (1\%). On the other hand, grid9 comprises a university area $(7.06 \%)$, existing house areas $(45.36 \%)$, technical infrastructure $(0.07 \%)$, trade areas $(5.69 \%)$, social areas $(0.52 \%)$, neighborhood sport areas $(0.78 \%)$, health service areas $(3.46 \%)$, government agency areas $(0.59 \%)$, recreation areas $(1.96 \%)$, median strips $(0.13 \%)$, park and playground areas $(8.24 \%)$, private education areas $(0.13 \%)$, educational areas $(3.40 \%)$, forest areas $(0.46 \%)$, suggested housing areas $(16.99 \%)$, a creek-canal $(0.78 \%)$, afforestation areas (0.78), places of worship (0.65\%), state railway areas $(2.09 \%)$, and fuel areas $(0.59 \%)$. Although both grids have significant empty space for proposed housing, we observed that the social infrastructure support that would be necessary after 
urban development, such as green spaces and healthcare units, is not adequate, and that no scenario to meet this need has been proposed. As stated, each grid covers an area of $1 \mathrm{~km}^{2}$; therefore, there is an apparent need for additional space to support the social infrastructure within the grid.

This research methods helps to determine the adequacy of land use distribution and demonstrates how creating these grids can guide urban development administrators in their decisions for future development. Similarities and differences found in cluster analysis help us determine the extent to which the existing members of a good urban infrastructure are sufficient as well as what is still needed. By presenting an alternative approach, this method helps to revise urban development plans and develop better approaches to future development.

In our study, using the grid approach allowed us to reveal any insufficiency in the social infrastructure within the city. The need to overcome these insufficiencies in social infrastructure in future urban development is highlighted. The results of the analysis show that green areas and other social services mentioned in planning practices are not evenly distributed among close, far, and neither close nor far grids. For example, grid1 has a green area ratio of $96.4 \%$ - a large amount of green areas. The fact that urban pressure on green areas and that some social service areas in urban development encroach on green areas indicates that, in the future, urban areas will be developed in these areas. Thus, the municipality's development proposals should protect green areas within administrative limits. In addition, this clearly shows that urbanization has yet to begin in grid 1; therefore, green area standards are very high while social infrastructure, such as healthcare and education, is insufficient in this grid according to Turkey's planning standards, such as that requiring that a primary school should be within $500 \mathrm{~m}$ from residential areas. As mentioned, to balance this distribution through planning, we can calculate the balance of the distribution of green areas and other services within these grids, which are either higher or lower than the standards. For example, when we calculate green areas without distinguishing between passive and active green areas, only grid3 displays a problem, while grids 2 and 28appear to have achieved the standards. On the contrary, grids 2 and 28are insufficient in terms of land available for healthcare services, while grids 5 and 9 have sufficient land designated for healthcare. Land use planning in these areas was unbalanced with respect to healthcare services. To better understand land use patterns in the next stage of our study, we examined the correlations among the grids.

Using a correlation analysis, the relationships among grids can be understood more clearly. Analyses of land use in urban development helped us to determine the interplay among the grids as well as to identify the variables that shape the future direction of development. The correlation analysis revealed the development pattern of the city's land. The analysis shows that insufficient social infrastructure (such as healthcare facilities) in grids 2 and 28 are among the city's biggest problems. Considering the tourism factor that is characteristic of the city, which was revealed using correlation analysis, this problem should be considered a priority and must be addressed in any new developments.

When examining the social infrastructural units in detail within the grids, grids 11 1223 and 29 attracted our attention. In the cluster analysis, we found that healthcare services came together in clusters 1 and 2 . Access to healthcare services was within $\sim 2-$ $3 \mathrm{~km}$ between the grids. In grid one state-owned hospital provides full healthcare services. When we assessed the distribution of the existing residential areas, we 
observed that grids 122.2 and 30 were within $6-7 \mathrm{~km}$ of the hospital, which is relatively far in emergencies. Even if there is no space for healthcare within a reasonable distance, our analysis showed that roadways to hospitals from more distant grids and providing alternative transportation options are suitable alternatives.

To investigate the relationship among grids in cluster analysis in more detail, a correlation analysis was conducted on land use. A strong correlation of 0.99 was found among the grids and among daily travel areas. Moreover, there is a noteworthy correlation of 0.95 between daily travel areas and archeologically protected areas. The same correlation was observed between technical infrastructure areas and industrial areas. Because the transportation network in Amasya is central, a strong correlation among the grids and the archeologically protected areas and daily travel shows the strength of the city's tourism potential. In addition, we can prove a dependency for the development of industrial areas on technical infrastructure areas through the correlations found in terms of land use.

\section{Discussion}

Cluster analysis was used to statistically explain where similar land use areas were concentrated. Cluster analysis is an important method by which to identify similar planning approaches in areas with the same land use characteristics and urban development, for determining any existing deficiencies in social facilities, and for gaining an understanding of social transport distances. In addition, this analysis serves to determine which clusters yield positive or negative results on a region-by-region basis.

Agglomerative hierarchical cluster analysis yielded very important findings for Amasya, including how land use is distributed and how land use should be planned. Mcharg (1992) is credited with having developed a land suitability model to ensure a healthy and balanced land use structure; however, our study failed to discern an approach to identify the social facilities in the current planned area or to provide development based on such an approach.

A development plan that identifies areas lacking social facilities and how to eliminate these deficiencies is important because it helps to make our cities healthier and more livable. Land structure and transport are significant factors that affect development planning; therefore, despite the improvements we have achieved, the issue of the lack of social facilities within the city must be resolved to the greatest extent possible. Although the situation that emerged when we examined the grids in terms of transport distances appeared to be positive, particularly for the healthcare sector, the same could not be said about access to a full-service hospital.

It is found that spatial land use arrangement and development is the main planning approach for the healthy future development of the cities. Cortinovis et al. (2019) were also examined urban spatial development and were emphasized the spatial arrangement of land uses as a crucial issue in their research. The healthy distribution of social infrastructure is one of the key point to prove sustainable urban development in the cities.

We were able to examine both the existence and the lack of social infrastructure areas within the grids in this research. It is worth noting here that the results from the analysis demonstrated that the distribution of the social infrastructure was neither satisfactory nor within the boundaries that delineated accessibility. In making these 
determinations, the social infrastructure facilities that were within $\sim 500 \mathrm{~m}$ of the center of the grids, in terms of accessibility, were taken into consideration.

A particularly remarkable finding was that the healthcare facilities were generally concentrated in clusters 1 and while the educational facilities were largely concentrated in clusters and 4 . Given that clusters 1 and 2 were mostly within the city's center, the social facilities within these clusters were more accessible and numerous. Although the lay of the land appears to have negatively affected the social infrastructure balance in areas outside the city's center, grids 19 and 24 within the city's center appeared to also experience the same negative impact because of the topography of its land.

In addition, not all of the educational institutions were at the same level of accessibility; that is, when we made the distinction among primary schools, we observed that not all educational facilities were within the $500 \mathrm{~m}$-perimeter accessibility boundary. According to the results of the analysis of the land use map, planning decisions dictating that the planning areas within clusters be included as part of the planning activity are important for ensuring that the same planning perspectives can be established. Cluster analysis enabled us to define the areas in which a similar planning approach should be conducted. Grid analysis, which helps to evaluate accessibility and similarity, sheds light on how urban planning should be pursued.

The methods used in this research are proposed important approaches to helping to implement plans for healthy urban development. The similarities and differences identified within the grids through hierarchical cluster analysis provide important clues oriented toward urban development decisions. In addition, they help identify the shortcomings in urban social infrastructure, which is a key component of urban development, and help to make recommendations accordingly.

The grid system is an analytical tool that is frequently used with raster data and infrequently used for urban social services. The grids were developed to generate information about how urban areas are developed. This study used grids to enable a more detailed examination using vector data for the first time to analyze urban social services. Grids were formed using GIS and the Hawth's analysis tool, which is frequently used by ecologists and biologists, to create an essential guide to how urban areas are developed. The cluster analyses conducted from grids using Minitab, the most appropriate was average linkage analysis. Differences among the grids were examined, and the social service areas in the grids were analyzed. The results of the analyses generated important clues about whether social services were or were not in each grid and where they should have been located.

The analyses of the grids revealed the inadequacy of educational space, healthcare space, and space for parks and gardens. In this respect, authorities should take such social infrastructural spaces into consideration when making decisions about areas of urban development. The methods used in this study offer a new understanding and approach to urban development plans in Turkey.

Into summarize, this study analyzed whether the uses of space for social infrastructural, green area, tourism, commercial enterprises, educational facilities, and similar other social services are adequate and balanced in Amasya's land use plans. In the analyses, the Amasya urban development plan was partitioned into 33 grids, each of which covering $100 \mathrm{Ha}$. Accordingly, analyses were performed within the grids that were categorized as follows:

- Grids that comprise a planned space between $~ 90 \%$ and $100 \%$,

- Grids that comprise a planned space of $\sim 50 \%$, and 
- Grids that comprise a planned space between $\sim 10 \%$ and $25 \%$.

We concluded based on these analyses that the City of Amasya Urban Development Plan was inadequate in its green area designations, and that it includes a faulty planning decision because it prescribes green spaces to be located at the extreme edges of urban space.

Our findings show the importance of a social infrastructure for a healthy urban environment. This fact, which this study makes apparent, is one of the most important elements to be discussed in approaches to urban development. A development plan's balanced distribution of social infrastructure in urban areas is important for a city's inhabitants. This study claims that urban land use is also significant for the development of social infrastructure.

\section{Conclusion}

The conclusion of this study found that a method by which to analyze an urban development plan can be balanced based on land use grids using cluster analysis. It also identified relationships between land use types using correlation analysis. There are several studies on land use; however, the focus of many is restricted to how land use has changed over the years. Unlike other studies, our study emphasizes the short comings in land use in terms of urban planning and identifies the deficiencies in the social infrastructural aspects of urban planning. The findings of this paper demonstrate that social infrastructure is insufficient in urban development and is not being distributed in a balanced way. In this sense, the focus is on the distribution of land use values in urban development, rather than on the changing values of land use in urban development. For example, a high density of green areas in one place and a lack of them in other places appears as an indication of whether that city is developing in a healthy and balanced way; therefore, this study brings a new perspective for future research. If we consider the findings of this study, we get a better understanding of the importance of social infrastructure in urban development.

In conclusion, the methods used in this study offer a new dimension to general land use and to the improvement of urban development plans in Turkey. These methods can be further improved in future studies because they provide a basis through which a new methodological approach can be used in other fields.

\section{REFERENCES}

[1] Alvarenga, R. A. F., Dewulf, J., Langenhove, H. V., Huijbregts, M. A. J. (2013): Exergybased accounting for land as a natural resource in life cycle assessment. - The International Journal of Life Cycle Assessment 1(9): 939-947.
[2] Anonymous
(2018):
COPHENET.

https://www.mathworks.com/help/stats/cophenet.html (accessed 15.09.2018).

[3] Bayo, J., Castellanos, J. L. (2016): Principal factor and hierarchical analyses for the performance assessment of an urban wastewater treatment plant in the southeast of Spain. - Journal of Chemosphere 152-162.

[4] Bo, H., Shu, L., Shu-hua, L. (2011): Ecological landscape planning and design of an urban landscape fringe area: a case study of Yang' an District of Jiande City. 2011 
International Conference on Green Building and Sustainable Cities. - Procedia Engineering 21: 414-420.

[5] Cinelli, M., Coles, S. R., Kirwan, K. (2014): Analysis of the potentials of multi criteria decision analysis methods to conduct sustainability assessment. - Journal of Ecological Indicators 46: 138-148.

[6] Cortinovis, C., Haase, D., Zanon, B., Geneletti, D. (2019): Is urban spatial development on the right track? Comparing strategies and trends in the European Union. - Journal of Landscape and Urban Planning 18: 22-37.

[7] Dearing, J. A., Ademola, K. B., Anette, R., Billie, L. T., Sander, van der L. (2010): Complex land systems: the need for long time perspective to assess their future. Ecology and Society 15(4): 21: 1-19.

[8] Erickson, D. (1995): Rural land use and land cover change. - Journal of Land Use Policy 1(3): 223-236.

[9] Everitt, B. S. (2005): An R and S-PLUS ® Companion to Multivariate Analysis. Springer, London.

[10] Foley, J. A., Defries, R, Asner, G. P., Barford, C., Bonan, G., Carpenter, S. R., Chapin, F. S., Coe, M. T., Daily, G. C., Gibbs, H. K., Helkowski, J. H., Holloway, T., Howard, E. A., Kucharik, C. J., Monfreda, C., Patz, J. A., Prentice, I. C., Ramankutty, N., Snyder, P. K. (2005): Global consequences of land use. - Journal of Science 309(5734): 570-574.

[11] Governorship of Amasya (2017): City Guide of Amasya. - Publication Number 38. www.amasyakulturturizm.gov.tr/Eklenti/706rehber-tr-mailpdf.pdf?0 (accessed 25.09.2017).

[12] Grecchi, C. R., Gwyn, Q. H. J., Bénié, G. B., Formaggio, A. R., Fahl, F. C. (2014): Land use and land cover changes in the Brazilian Cerrado: a multidisciplinary approach to assess the impacts of agricultural expansion. - Journal of Applied Geography 55: 300312.

[13] Hubacek, K., van den Bergh, J. C. J. M. (2006): Changing concepts of 'land' in economic theory: from single to multi-disciplinary approaches. - Journal of Ecological Economics 56: 5-27.

[14] Kline, J. D., Thiers, P., Ozawac, C. P., Yeakley, J. A., Gordone, S. N. (2014): How well has land-use planning worked under different governance regimes? A case study in the Portland, OR-Vancouver, WA Metropolitan Area, USA. - Journal of Landscape and Urban Planning 131: 51-63.

[15] Krekel, C., Kolbe, J., Wüstemann, H. (2016): The greener, the happier? The effect of urban land use on residential well-being. - Journal of Ecological Economics 121: 117127.

[16] Lance, G., N., Williams, T. (1967): A general theory of classificatory sorting strategies 1. Hierarchical system. - The Computer Journal: 373-380.

[17] Liu, Y., Yang, R., Long, H., Gao, J., Wang, J. (2014): Implications of land-use change in rural China: a case study of Yucheng, Shandong Province. - Journal of Land Use Policy 40: 111-118.

[18] Lu, X., Ke, S. (2018): Evaluating the effectiveness of sustainable urban land use in China from the perspective of sustainable urbanization. - Journal of Habitat International 7: 9098.

[19] Manjunath, M., Zhang, Y., Kim, Y., Yeo, S. H., Sobh, O., Russell, N., Followell, C., Bushell, C., Ravaioli, U., Song J. S. (2018): ClusterEnG: an interactive educational web resource for clustering and visualizing high-dimensional data. - Peer J Comput. Sci. 4: e155. DOI: $10.7717 /$ peerj-cs.15.

[20] McHarg, I. L. (1992): Design with Nature, $25^{\text {th }}$ Anniversary. - John Wiley and Sons Inc., Hoboken, NJ, pp.1-198.

[21] Milesia, C., Elvidgeb, C. D., Nemania, R. R., Running, S. W. (2003): Assessing the impact of urban land development on net primary productivity in the southeastern United States. - Journal of Remote Sensing of Environment 86: 401-410. 
[22] Mooi, E., Sarstedt, M. (2011): A Concise Guide to Market Research. The Process, Data, and Methods Using IBM SPSS Statistics. - Springer, Berlin.

[23] Murtagh, F., Legendre, P. (2011): Ward's hierarchical clustering method: clustering criterion and agglomerative algorithm. - arXiv:1111.6285.

[24] Niedertscheider, M., Erb, K. (2014): Land system change in Italy from 1884 to 2007: analysing the north-south divergence on the basis of an integrated indicator framework. Journal of Land Use Policy 39: 366-375.

[25] Nuissl, H., Haase, D., Lanzendorf, M., Wittmer, H. (2009): Environmental impact assessment of urban land use transitions. A context-sensitive approach. - Journal of Land Use Policy 26: 414-424.

[26] Ozus, E., Akın, D., Çiftçi, M. (2012): Hieararchical cluster analysis of multicenter development and travel patterns in İstanbul. - Journal of Urban Planning and Development 138: 303-318.

[27] Paffi, M., Siragusa, A., Ferri, S., Halkia, M. (2016): Measuring the accessibility of urban green areas. - JRC Technical Reports, Publications Office of the European Union. http://publications.jrc.ec.europa.eu/repository/bitstream/JRC102525/190916_siragusa_\% 20jrc_techrep_accessibility_online.pdf (accessed 19.01.2018).

[28] Randolph, J. (2004): Environmental Land Use Planning and Management. - Island Press, Washington, DC.

[29] R Core Team (2015): R: A Language and Environment for Statistical Computing. - R Foundation for Statistical Computing, Vienna. http://www.R-project.org/ (accessed on 3 March 2017).

[30] Robinson, M. G. (1998): Methods and Techniques in Human Geography. - John Wiley and Sons Ltd., Chichester.

[31] Sharifi, A., Chiba, Y., Okamoto, K., Yokoyama, S., Murayama, A. (2014): Can master planning control and regulate urban growth in Vientiane, Laos? - Journal of Landscape and Urban Planning 131: 1-13.

[32] Shi, P., Yu, D. (2014): Assessing urban environmental resources and services of Shenzen China: a landscape-based approach for urban planning and sustainability. - Journal of Landscape and Urban Planning 125: 290-297.

[33] Singh, S. J., Haberl, H., Chertow, M., Mirtl, M., Schmid, M. (2013): Long-Term SocioEcological Research. Studies in Society: Nature Interactions Across Spatial and Temporal Scales. - Springer, New York, pp. 1-561.

[34] Song, Y., Merlin, L., Rodriguez, D. (2013): Comparing measures of urban land use mix. - Journal of Computers, Environment and Urban Systems 42: 1-13.

[35] Turkstat (Turkey Statistical Institute) (2012): Chosen Indicators of Amasya. - Publication Number 408. www.tuik.gov.tr/ilGostergeleri/iller/AMASYA.pdf (accessed 10.08.2014).

[36] Turkstat (Turkey Statistical Institute) (2018): Population Report of Amasya, Central Dissemination System. - https://biruni.tuik.gov.tr/medas/?kn=95\&locale=en (accessed 31.03.2019).

[37] Türk, S., S. (2002): Land development and realization of local physical plans in urban areas in Turkey: a model. - FIG XXII International Congress, Washington DC. https://www.fig.net/resources/proceedings/fig_proceedings/fig_2002/Ts8-

1/TS8_1_turk.pdf (accessed 20.06.2016). 